\title{
PRODUCT DEVELOPMENT USING TEXTILE WASTE
}

\section{DEEPTI SETHI \& AMITA WALIA}

Department of Fabric and Apparel Science, Institute of Home Economics, University of Delhi, New Delhi, India

The textile industry has been seen as a major contributor of industrial waste, and has always been quoted negatively. Although this industry itself has a capacity of reducing and reusing this waste, it needs to find the ways to reuse and recycle the solid waste being generated by it. The main objective of this study is, innovative usage of waste material collected from export house. The focus is to reduce the environmental damage being caused by the solid waste, by creatively using it to make a product range.

The students' 'Product Development Using Textile Waste' is an effort to transform the surplus material into a product. A variety of surplus fabrics and materials were sourced from the export houses, to conduct the study. Various fabric manipulation techniques were explored on the different fabric base, conforming to the properties of the fabrics.

Fabric manipulation includes the techniques that refashion the fabric in its physical appearance, by adding value to it. These techniques include shirring, smocking, gathering, quilting, appliqué', Cutwork and many more. These techniques, once developed were groomed and transformed into a bedroom collection. Hence, a range of products was developed that was not only design-based but eco-friendly, as well.

KEYWORDS: Reuse, Textile Waste, Fabric Manipulation Techniques \& Product Development
\end{abstract}

Received: May 03, 2017; Accepted: May 23, 2017; Published: Jun 05, 2017; Paper Id.: IJTFTJUN20173

\section{INTRODUCTION}

The textile industry has been ranked as the second biggest as a trade activity and employs more than 25 million people. Along with that, it can also be seen as the fastest growing sector of solid waste. This waste can further be categorized into two-

- Waste generated at construction level

- Waste generated at the consumer level

The first type of waste is being hugely generated during production processes. Either, the cut pieces are added to the landfills, or the surplus fabrics are left untreated to decompose. The other waste is that, which is generated by the consumers, who are discarding the products without using them completely.

With the changing times, the scenario is changing. Consumers are concerned about the environment and they are ready to accept the eco-friendly ways. The R's -Reduce, Reuse and Recycle are seen as the most appropriate direction to control this problem. In the present study, the focus was on the waste being generated during production processes. The efforts were made to reuse waste material in the best possible manner. 


\section{OBJECTIVES}

- To collect and segregate the waste from various manufacturing units.

- To develop a catalogue of various fabric manipulation techniques

- To design and develop a 'top of the bed' range by reusing the waste material collected.

\section{METHODOLOGY}

The study was carried out by keeping the given objectives in mind and was divided into the following phases:

Phase 1

Market Survey

Collection of raw material

\section{Market Survey}

The first stage was to conduct a market survey, to understand

- Availability of the products with surface ornamentation and fabric manipulation

- Prevalent styles of the biddings

- Various combinations of the products

- Prices of the similar products available

\section{Collection of Raw Material}

During this stage, various manufacturing units were visited to collect the waste and surplus material.

\section{Phase 2: Development of Techniques}

During the second phase, samples of various fabric manipulation techniques were developed using the collected waste material. The materials used were a mix of solid colored and printed fabrics. Various fabric manipulation techniques were explored on the different fabric base, conforming to the properties of the fabrics. After initial experimenting, fabric and techniques with the best result, in terms of appearance and efficiency, were selected and catalogued.

\section{Phase 3: Designing \& Development of Product Range}

Development of Mood Boards and Color Boards

To achieve the objective of product development, using surplus material, forecasts for home furnishings, texture and color were studied and 'Spring' was selected as the theme. With this theme, mood boards and color story was developed using computer software - Photoshop. From the forecasts white, red and green colors were selected for the final range.

\section{Design Placements Using CAD}

Various placements and layouts were sketched using CorelDraw. The combination of sizes of the products was also sketched using CAD. 


\section{Product Development}

A few techniques from the catalogue were selected to develop the product range. Mood board, colour board and forecasts were considered for the selection of colour and texture.

The one of placement sketched was selected to place the layered flower on the different products.

\section{Cost Estimation and Evaluation}

The cost evaluation of each product was done separately and cost of the complete product range was finally calculated. Further, the constructed products were evaluated by the panel of judges based on the visual appearance, design, quality and price of the products.

\section{RESULTS AND DISCUSSIONS}

\section{Phase 1}

\section{Market Survey}

To establish an authentic knowledge, a market survey was conducted. It was found that fabrics used for beddings were in cotton, silk, velvet, satin, etc., whereas, fabrics for curtains varied from glass tissue, raw silk, khaddar silk, khaki cotton, khaki polyester, organza, cotton, chenille, etc.

The products focussed on being bed covers, shams, pillows and cushions. It was found the size of king size bedcover is 110" x 96", 110" x 106" and 112" x 116". The size of the queen size bed cover was 90" x 100". The size of oblong accent pillows was 12" x 16", 12" x 18" and 12" x 60". Available size for the shams was 26 sq. inch, 20" x 30", whereas the dimensions of the cushions were 8" x 8", 12" x 12", 16" x 16" and 22" x 22".

It was found that the ornamentation done on these products were embroidery, patchwork, sequence, etc. These techniques were extensively used in these products.

\section{Collection of Raw Material}

Various manufacturing units, naming, Maharani of India and Yudhishthra Kapur Exports Pvt. Ltd were visited to collect the waste material and surplus material. The cut pieces left after the cutting of the complete garments are categorized as waste material. The balance fabric left, once all the goods are shipped to the brand, is categorized as surplus fabric.

Meetings were arranged with fabric (and accessory) store managers to understand the disposal of waste material and cycle of surplus material. It was ensured that the material collected was leftovers from the styles that have been shipped at least a month ago.

\section{Phase 2: Development of Techniques}

The researcher has developed a number of samples using various fabric manipulation techniques like, shirring smocking, trap unto, cord quilting, fabric weaving, bubbling, pin weaving, origami, etc. The supporting material required to develop these techniques were cotton yarn, wooden frames, cotton balls, wire mesh, pressure cooker, rubber bands etc. The waste material was procured from various manufacturing units for developing a catalogue of fabric manipulation techniques. The focus was to ensure utilization of waste material in a productive manner. The fabric manipulation techniques were explored on the different fabric base, conforming the properties of the fabrics. Each technique show 
different effect, in terms of appearance, on different fabrics.

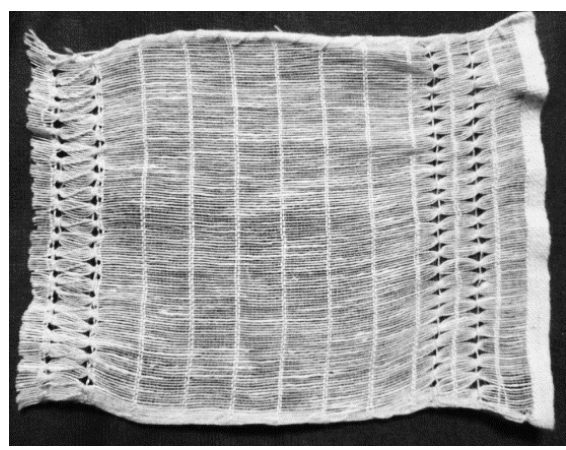

Figure 1(A): Fabric Manipulation Technique 1

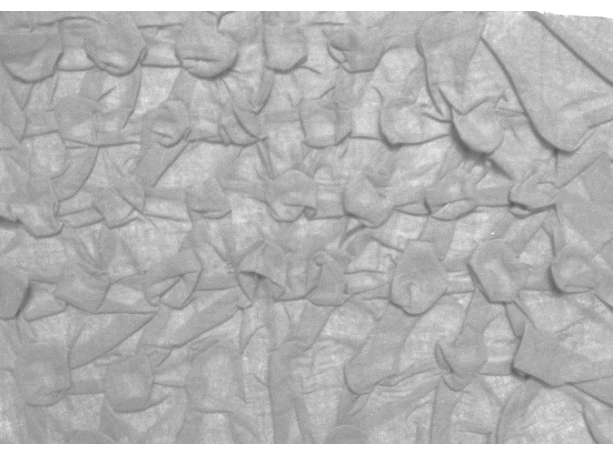

Figure 1(B): Fabric Manipulation Technique 2

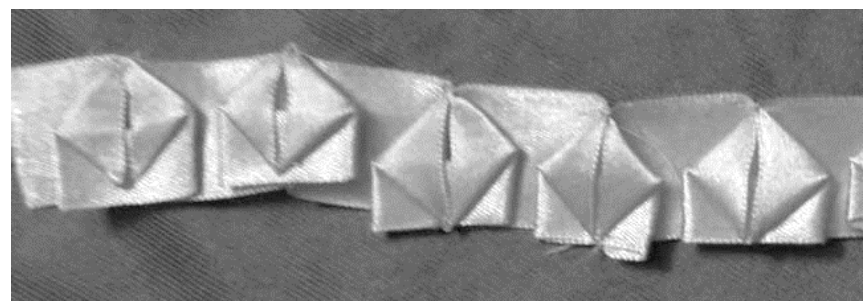

Figure 1(C): Fabric Manipulation Technique 3

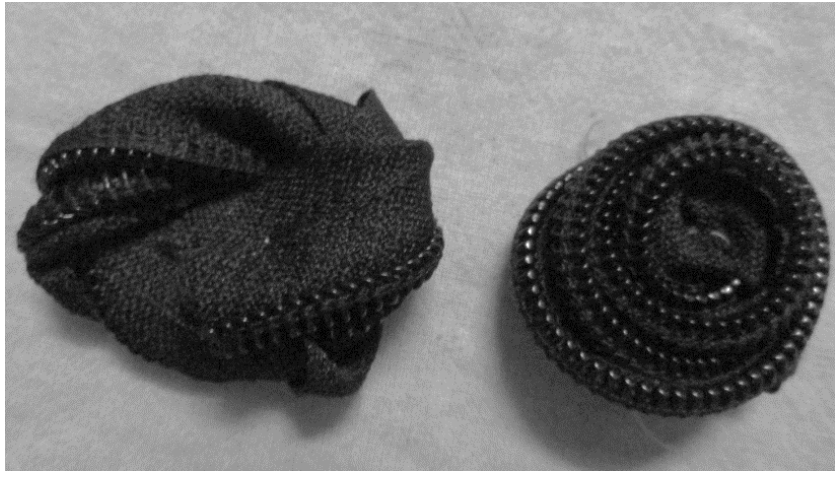

Figure 1(D): Fabric Manipulation Technique 4

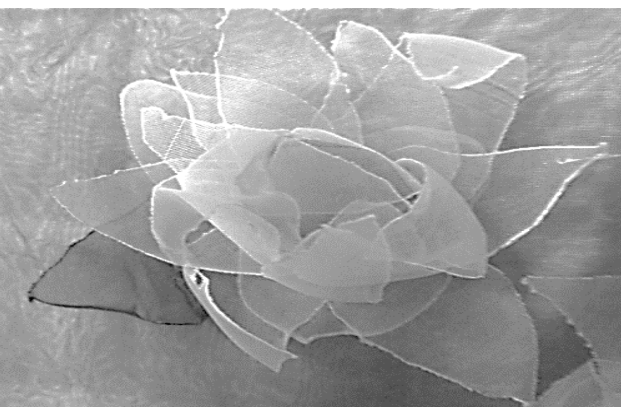

Figure 1(E) Fabric Manipulation Technique 5

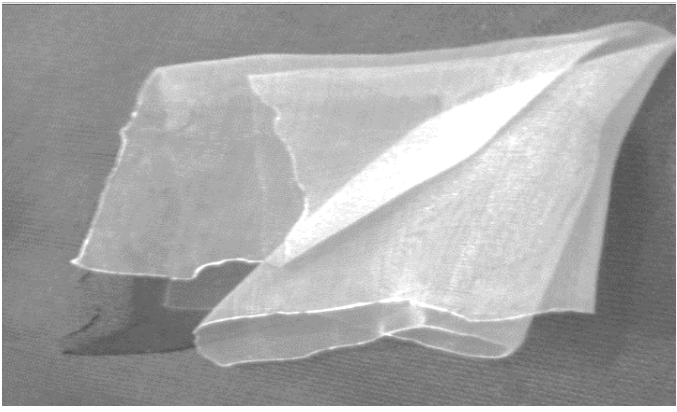

Figure 1(F) Fabric Manipulation Technique 6 


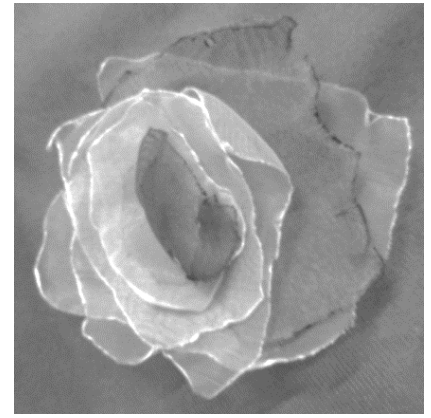

Figure 1(A) Fabric Manipulation Technique 7

Figure 1: Various Fabric Manipulation Techniques

\section{Phase 3: Designing and Development of Product Range}

\section{Development of Mood Board \& Colour Board}

A number of mood boards in various combinations were developed using computer software Photoshop. The theme selected for the bedroom collection was 'spring'.

For the development of the product range white, red and green colors were selected from the mood board and the forecasts referred.

\section{Design Placement Using CAD}

Various layouts and placements were sketched on the computer, using Photoshop and Corel Draw. Various combinations and placements of shams, pillows and cushions were tried. Layouts for curtains and bed cover were also worked out.

\section{Product Development}

After sketching of various layouts, the researcher constructed the products according to the theme. Mainly glass tissue and chenille fabrics were chosen for the fabric manipulation techniques. Poplin was used for the base and back of the product. 


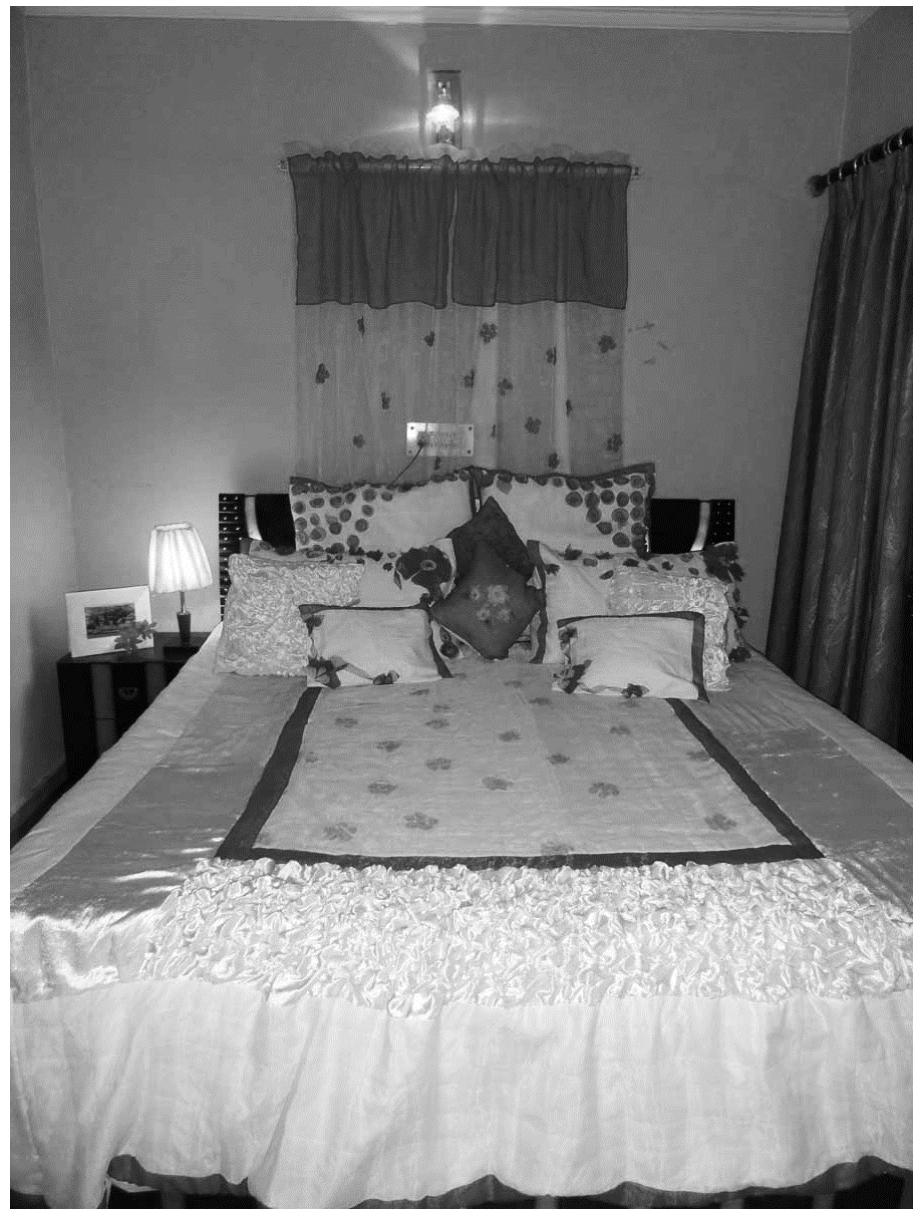

Figure 2: Product Range Developed Using Fabric Manipulation Techniques

The products developed are - One Bedcover, a set of curtains, set of Euro shams, set of standard shams, and set of accent pillows, two cushions, a lampshade and a photo frame.

The bedcover was developed in 9 panels, in which four outermost panels were quilted, same as shams and cushions, with a red border. Then, chenille was used, on three sides, its plain and on one side, surface texturizing was done on chenille. The innermost layer is again quilted, with red flowers on cotton base and then, a layer of white glass tissue was used on the top.

The Shams, and Cushions were developed by cutting the base, where foam was sandwiched between the two layers of the pipeline. The topmost layer was white glass tissue on which red border was stitched on two sides. Further, these were decorated with stitching differently shaped flowers and leaves.

The curtains were developed using white glass tissue fabric as a base, on top of which, flowers and leaves stitched. A lamp shade and a photo frame were also made to accessorize the collection.

\section{Costing}

To calculate the price of the products, the cost of fabric (as per the consumption) and accessories, CMT (cost of cutting, making and trimming) and overhead expenses were calculated. 


\section{Evaluation}

The product range was presented to a panel of judges to evaluate on the criteria of visual appearance, design, quality and price. The aggregate score recorded on the basis of each criterion is listed below:

Table 1: Aggregate Scores Recorded During Evaluation
\begin{tabular}{|c|c|c|c|}
\hline Visual Appearance & Design & Quality & Price \\
\hline 5 & 4.5 & 3.5 & 5 \\
\hline
\end{tabular}

\section{CONCLUSIONS}

A large amount solid textile waste is the matter of concern. This waste is not only harming the environment, but also requires ample resources for disposing. To overcome this problem, the waste can be reused. It is important to understand that waste generating industry can reuse it, in innovative manners. In this study, the researcher has tried a step forward to present the new and creative idea for the utilization of the waste, available in the textile industry. The entire bedroom range was well appreciated by the experts. It might not be used as a whole, but could be used as a part of the product depending upon the type and size of fabric waste.

\section{ACKNOWLEDGEMENTS}

I would like to express my thanks to 'Maharani of India' and 'Yudishtira Kapur Exports Pvt Ltd' for allowing the waste material procurement.

\section{REFERENCES}

1. Sinha, Pammi, et al (2009) Recycled Fashion. In: Taking up the Global Challenge: 15th Annual International Sustainable Development Research Conference, 5 July, 2009, Utrecht University, and the Netherlands. Retrieved from http://eprints.hud.ac.uk/17252/1/final_paper.pdf

2. Cara Brower, Rachel Mallory \& Zachary Ohlman (2009). Experimental Eco-Design, Rockport Publishers 
